\title{
Endoscopically-Assisted Scar-Free Midline Neck Mass Excision
}

\author{
Hyoyeon Kim (D) · Seung Hoon Woo (i) \\ Department of Otorhinolaryngology-Head and Neck Surgery, Dankook University College of Medicine, Cheonan, Korea
}

\begin{abstract}
Traditional open surgery is indicated for the treatment of selected tumor subsites in the head and neck. However, it can cause major cosmetic problems and functional pathologies. The endoscopically-assisted transoral approach is increasingly preferred in some surgical fields due to its superior cosmetic and functional outcomes. Nonetheless, endoscopically-assisted transoral approach is not yet standard in the head and neck due to their anatomical complexity. The transoral surgical approach has been used for head and neck masses since the 1960s, and its application continues to evolve with changing disease conditions and recent innovations in surgical instruments. The potential for wide application of transoral surgery continues to be investigated, with a focus on minimizing occurrence of the complications. This review presents details of the surgical procedure and postoperative clinical outcomes, as well as endoscopically-assisted scar-free techniques for the resection of midline neck masses.
\end{abstract}

Keywords. Head and Neck Neoplasm; Endoscope; Surgical Wounds; Surgery; Transoral

\section{INTRODUCTION}

Surgical resection is generally required for both benign and malignant lesions of the head and neck. The most commonly accepted approach for resection is percutaneous incision. However, a transcervical percutaneous incision inevitably results in visible scarring, which can become hypertrophic or develop into keloids, even if the incision is parallel to skin wrinkles and expression lines. Postoperative cosmetic outcomes are an important consideration in surgery involving these areas, as the appearance of the head and neck is essential for social interactions [1,2].

Recent advances in endoscopic (or robotic) surgery have minimized or concealed incision scars. A recent surgical trend involves reducing the extent of surgery (including endoscopic surgery) in order to decrease morbidity, with equivalent results to those of conventional surgical methods. This approach is usually limited to benign lesions, but current efforts are intended to extend the

\footnotetext{
- Received December 13, 2020

Revised June 17, 2021

Accepted June 25, 2021

- Corresponding author: Seung Hoon Woo

Department of Otorhinolaryngology-Head and Neck Surgery, Dankook

University College of Medicine, 119 Dandae-ro, Dongnam-gu,

Cheonan 31116, Korea

Tel: +82-41-550-1781, Fax: +82-41-550-7837

E-mail: lesaby@hanmail.net
}

technique to malignant head and neck lesions [3,4].The transoral approach, in which incisions are placed more inconspicuously, achieves favorable cosmetic outcomes by eliminating noticeable scars. Recent studies evaluating the feasibility of endoscopic resection via the transoral approach for various benign or malignant lesions of the head and neck have yielded very meaningful results [5-15]. The transoral approach was significantly superior to the percutaneous approach in terms of cosmetic acceptability without significantly increasing complications or hospitalization.

However, endoscopic surgical methods have yet to be standardized for benign and malignant lesions involving the head and neck region due to the anatomical complexity of these areas. Therefore, attempts have been made to develop new approaches to conceal or eliminate incision scars generated during resection of head and neck lesions. Herein, we present an overview of progress to date.

\section{NEW SURGICAL METHODS}

Recent advances and innovations in medical therapeutics and technology have led to the development of scarless surgery. The most common approach entails surgery through a natural orifice in the body. This method is designated as natural orifice transluminal endoscopic surgery (NOTES), in which endoscopic access

Copyright @ 2021 by Korean Society of Otorhinolaryngology-Head and Neck Surgery.

This is an open-access article distributed under the terms of the Creative Commons Attribution Non-Commercial License (https://creativecommons.org/licenses/by-nc/4.0)

which permits unrestricted non-commercial use, distribution, and reproduction in any medium, provided the original work is properly cited. 
is achieved via the mouth, urethra, or anus. Several factors still need to be addressed for NOTES to be widely applicable in clinical settings, including safe sealing of the open surgical window that is created, the development of suitable devices, the selection of an appropriate access route, and the prevention and management of complications such as infections. Studies are needed to address these challenges. In surgery using NOTES on the head and neck [16], the endoscope is passed via the oral cavity into the internal organs. Only a mucosal incision is required for this approach. No skin incision is required. Transoral thyroidectomy was introduced as a type of NOTES, and some instances of applying transoral thyroidectomy have been reported [7,13,14,16-19].

We applied a transoral endoscopic approach (NOTES) for the treatment of different masses occurring in the head and neck area. Common masses in the midline neck area include dermoid cysts, thyroglossal duct cysts (TGDCs), and thyroid glands. All of these masses can be removed using this method.This approach entails a midline incision in the floor of the mouth and utilizes a natural midline incision between the genioglossus muscles (GMs). This area is relatively avascular, without nerves, and contains loose soft tissue. The mylohyoid muscles are naturally exposed when each side of the GMs is bilaterally retracted. (Fig. 1). The space below the mylohyoid muscle can be reached via an incision in the mylohyoid muscle, so this method provides a technically appropriate surgical field $[6,14]$.

Clinical application of this basic concept can provide easy access to midline neck masses. In this surgical method, incision of the oral cavity and retraction of GMs can be used to remove the object without damaging other structures. After surgery, patients are prescribed antibiotics for 3 days and are advised to gargle frequently $(0.02 \%$ chlorhexidine). Oral intake of a normal diet is permitted 1 day after surgery.

\section{Floor of the mouth and above the mylohyoid muscle}

The presence of a central cystic neck mass resting at the floor of the mouth and superior to geniohyoid muscle may cause posterosuperior tongue displacement, dysphonia, dysphagia, or airway obstruction, and such masses therefore usually indicated for surgical treatment. Here, we present dermoid cysts as a successful example of masses that can be removed in this area. Dermoid cysts are benign lesions that can occur throughout the body, with approximately $7 \%$ in the head and neck and $1.6 \%$ in the oral

\section{H I G G H L L I}

- The endoscopically-assisted transoral approach is becoming a preferred technique in many cases requiring surgery.

- Transoral excision is a potentially effective and safe method that leads to good cosmetic outcomes.

- Transoral midline neck mass excision is a good alternative to conventional transcervical surgery.
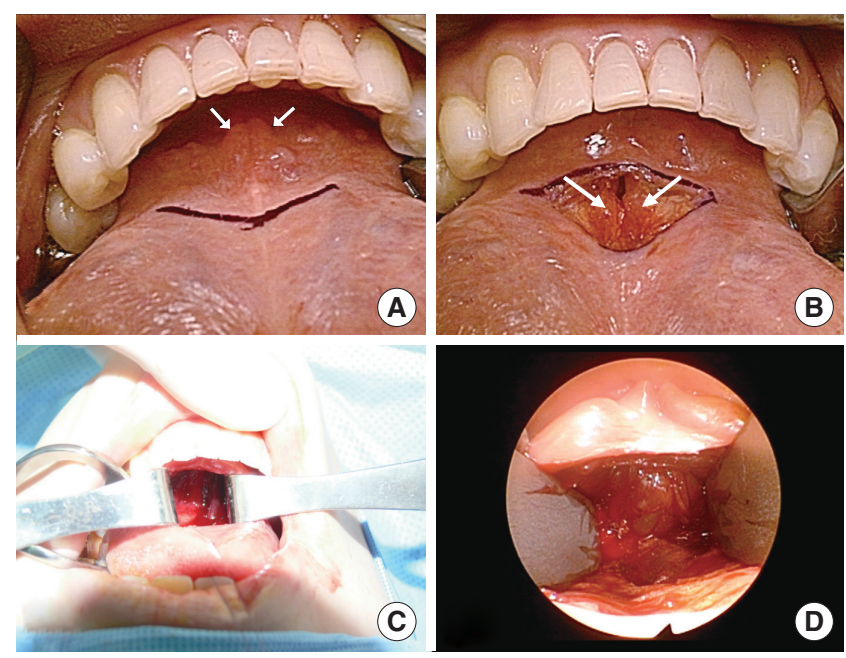

Fig. 1. (A-D) Transoral approach. After frenotomy, the genioglossus muscle (white arrows) is located and retracted bilaterally to facilitate the approach to the anterior neck area.

cavity [20].They usually present as slowly enlarging, symmetrical midline lesions. The first diagnosis, even in congenital cases, is usually made in young adults aged 20 to 30 years [21,22]. Dermoid cysts are usually diagnosed only after they reach a fairly large size, as they are primarily asymptomatic [23]. Dermoid cyst-induced swelling of the oral floor can cause serious problems with swallowing and conversation. The main complaints are tongue elevation, speech changes, and double chin development. It can also pose a significant risk to the airway $[24,25]$.

Surgical resection is the only effective treatment for dermoid cysts in the oral cavity, where the lesion size and location traditionally determine the surgical option. Many surgical techniques have been introduced to remove dermoid cysts of the mouth. The techniques include transcervical approaches, such as bilateral incisions along the mandibular condyle and median sagittal glossotomy to remove dermoid cysts via the intraoral or extraoral routes, depending on the size and location of the dermoid cyst. However, recent innovations and technological advances in surgery have rendered large skin incisions or glossotomy obsolete for treating benign dermoid cysts $[6,8,14,26,27]$.

The mylohyoid muscle has been regarded as a hindrance to the transoral approach. Anatomically, two types of dermoid cysts (associated with upper and lower mylohyoid muscles) exist according to the anatomical relationship between the cyst and the mylohyoid muscle on the mouth floor. An external approach is generally recommended if the cyst is below the mylohyoid muscle [23]. A transoral approach was used for a small cyst above the mylohyoid muscle [28]. This approach facilitates visualization of surrounding structures and control of bleeding, avoiding oral contamination of surgical wounds [29]. In fact, the surgical field is restricted during the transoral approach, and making a large incision to secure the surgical field increases the risk of lingual 
nerve damage in the Wharton's canal. However, advances in endoscopic and other medical device technologies have enabled removal of tumors in the lower part of the mylohyoid muscle without complications associated with the transoral approach.

\section{SURGICAL TECHNIQUES}

Under general anesthesia, the mouth is opened with a Denhart oral retractor or Dingman retractor. The tongue is then retracted upwards. A horizontal incision is made on the frenulum mucosa of the tongue above the opening of the submandibular gland. Next, the GM is identified in the surgical field. The GM contains two components: one on the left and the other on the right. The GM is retracted to each side using a Sofield retractor (233-04; Zimmer Biomet, Warsaw, IN, USA) to locate the dermoid cyst above the mylohyoid muscle (Fig. 2). If the cyst is below the mylohyoid muscle, a Bovie electrocautery device is used to cut the mylohyoid muscle. The dermoid cyst is then carefully separated with an endoscopic dissector (Aesculap Inc., Center Valley, PA, USA) and removed through the incision in the oral cavity. The surgical field is irrigated without any insertion of drainage. This procedure, which involves a simple mucosal incision and muscle retraction, results in very little secretion because it minimizes damage to muscles and bones. The oral mucosa is then sutured vertically, as horizontal sutures can lead to wound contracture, which can reduce tongue movement.

\section{Below the geniohyoid muscle and around the hyoid bone}

The most common type of cervical mass typically located in the midline, especially below geniohyoid muscle and around the hyoid bone, is TGDC. It is the most common congenital neck mass in children [30], constituting more than $70 \%-75 \%$ of all cases [31,32]. Treatment of TGDC requires a profound understanding of its embryogenesis $[33,34]$. The thyroid gland extends from the tongue base to the anterior lower neck, and the residual tract, which is called the thyroglossal duct (TGD), represents signs of movement [34]. MostTGDs degenerate during development, but if ducts remain along the thyroid migration tract, they can cause cysts of the epithelial tract and increase the likelihood of TGDC development [34]. It is generally estimated that $7 \%$ of the adult population has TGDs [29]. Currently, approximately 25,000 to 30,000 patients exist in South Korea [7,9,35].

The Sistrunk procedure, which is widely accepted as the only effective surgical treatment for TGDCs, involves excision of the mid-portion of the hyoid bone with the cystic area and removal of the TGD between the foramen cecum at the tongue base and the hyoid bone to prevent cyst recurrence [36-40]. Recurrence occurs in fewer than $10 \%$ of patients undergoing conventional TGDC surgery. The conventional method leaves a cervical scar [34,37,39-41]. Furthermore, it is difficult to approach the entire TGD in the traditional operation. In children, the TGD is situated
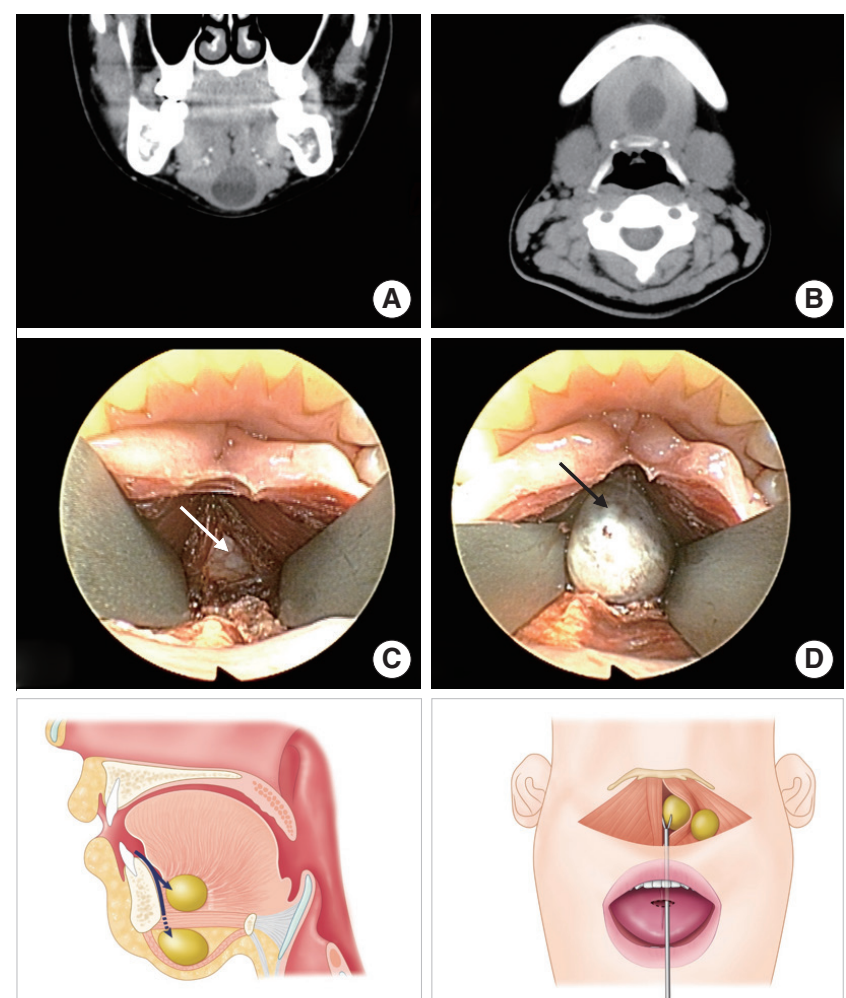

(E)

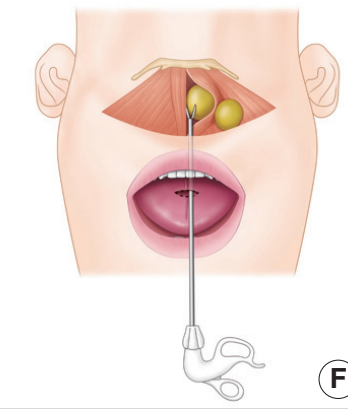

(F)

Fig. 2. Transoral approach via a midline incision in the floor of the oral cavity. (A, B) Computed tomography reveals a neck mass beneath the mylohyoid muscle. $(C)$ An incision is made in the midline of the floor of the oral cavity through a frenulum. After dissecting the soft tissue of the floor of the mouth, the genioglossus muscle is separated at the midline and retracted bilaterally (white arrow). The mylohyoid muscle is then exposed. Endoscopic guidance can identify mass-like lesions after mylohyoid muscle resection. (D) After dissecting the soft tissue around the mass (black arrow), it is removed. (E) Transoral approach for a neck mass at the floor of mouth and above the mylohyoid muscle. Anatomical view. Surgical approach to locate dermoid cysts below or above the mylohyoid muscle (arrows). (F) Surgical view. Removal of a dermoid cyst using an endoscopic dissector through the mucosal horizontal incision at the tongue frenulum.

at the tongue base and located distant to the percutaneous incision site, obscuring duct identification. Considering the postoperative external scar and embryological aspects, alternative surgical approaches are needed to obtain access to the entire TGD without leaving scars.

Based on our detailed experience of real-time application of these procedures, the next section will introduce thyroid cyst surgery via the transoral approach. The transoral approach presented here allows surgeons to easily identify the TGD, the hyoid bone, and TGDCs. In particular, it is easy to find the TGD from the tongue base to the hyoid bone between the GMs (natural dehiscence) when the GMs are retracted bilaterally. In a pre- 
vious study, TGDs were identified during surgery in $81 \%$ of patients who underwent the transoral approach, but in only $67 \%$ of those who underwent conventional surgery $[9,35]$. These results are attributed to the anatomy of the TGD, which is thin and difficult to fully access in traditional surgery, where skin incisions and surgical fields are narrow. Furthermore, the TGD is soft and easily dissected. However, the full-length TGD cannot be excised, which is concerning because residual TGD may increase the TGDC recurrence rate.

During the resection of TGDC in children, the hyoid bone is located higher than in adults. Therefore, using the transoral approach, surgeons can easily find cysts located within $3 \mathrm{~cm}$ of the oral mucosal incision. Moreover, the hyoid bone of pediatric patients is not as ossified as that of adults, so it is very easy to cut. These two features facilitate excision of TGDCs in children compared to adults. In addition, studies reporting transoral TGDC surgery in the neck have recently been performed in children. In the author's experience, the youngest patient was a 2-year-old girl, and after 5 years of follow-up, no recurrence or complications in pronunciation or swallowing were detected. In addition, the transoral approach creates a logically accessible route to TGDCs, given the embryological development of TGDCs. This study was performed after obtaining the approval of the Institutional Review Board at Gyeongsang National University Hospital (IRB No. GNUHIRB-2010-09-013-001) and all patients were registered after submitting written informed consent.

\section{SURGICALTECHNIQUES (TRANSORALTGDC EXCISION)}

The basic procedure for transoral TGDC excision corresponds to traditional TGDC excision, with the only difference involving the approach $[37,38,40]$. Under general anesthesia, the patient's mouth is opened with a Denhart retractor and the tongue is retracted upwards. A horizontal incision is made on the frenulum mucosa of the tongue, which is located above the opening of the submandibular gland. Next, the GM is identified in the surgical field. Surgical dissection is performed under a magnified endoscopic view (rigid body, $10 \mathrm{~mm}, 0$; Olympus, Tokyo, Japan). The surgeon dissects between the two parts (left and right) of the GM to locate the avascular space between those parts. The GMs are pushed to each side with Sofield retractors (Zimmer Biomet, Warsaw, IN, USA) to locate the TGD from the foramen cecum to the hyoid bone. The operator separates the TGD from the muscles of the tongue and then cuts it just below the foramen cecum and the hyoid bone. The whole TGD is finally identified using an endoscopic dissector device and ultrasonic scissors. The hyoid bone is then dissected and cut to a length of $1 \mathrm{~cm}$ with an osteo-punch rongeur. When the dissected hyoid bone is pulled up, the attached TGDC is pulled together. The surgeon carefully dissects each cyst and removes it through the incision in the oral
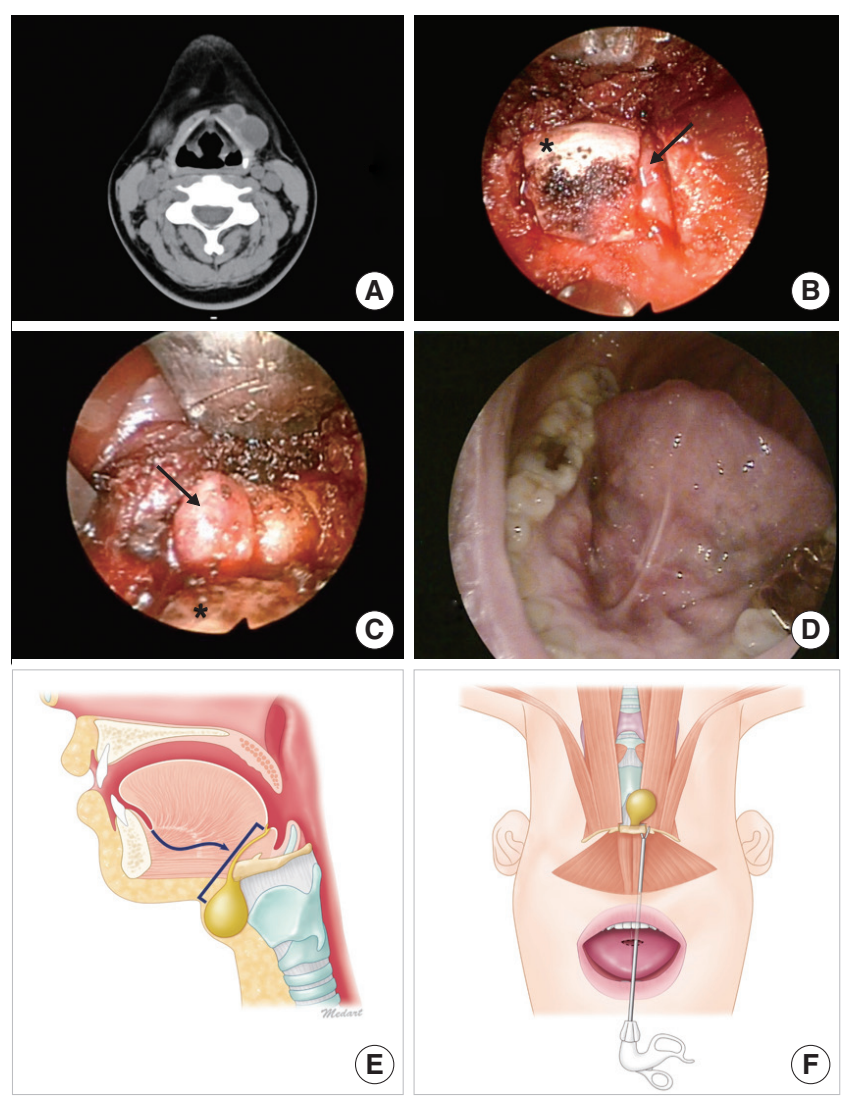

Fig. 3. Transoral thyroglossal ductal cyst excision. (A) Computed tomography reveals two thyroglossal ductal cysts as midline neck masses. (B) A vertical incision is made through the frenulum at the midline of the floor of the oral cavity. After dissecting the soft tissue, the hyoid bone (asterisk) and thyroglossal duct cyst (TGDC; arrow) are identified. (C) After cutting the hyoid bone with a 1-mm osteopunch rongeur, the TGDC (arrow) attached to the hyoid bone (asterisk) is removed via careful incision of the cyst, while pulling the hyoid bone upward. (D) Oral cavity scar at 1 month postoperatively. (E) Transoral approach for neck mass below the geniohyoid. Anatomical view. Surgical approach to locate the TGDC (arrow) and overall range of surgery. (F) Surgical view. Removal of the TGDC altogether with the dissected hyoid bone.

cavity (Fig. 3). The operation field is irrigated. The operator reattaches the GM using 4-0 Vicryl and sutures the oral mucosa vertically.

\section{Thyroid and perithyroid area}

Thyroid masses are the most frequently encountered type of anterior neck mass. Thyroid cancer is steadily becoming more widespread, and it is the most common cancer in women. The majority of patients are now diagnosed at an early age [14,18,42]. Most patients undergoing thyroidectomy have an excellent oncologic prognosis. Current open thyroidectomy allows direct access to the surgical site to enable safe and quick surgery, resulting in lower morbidity. However, this procedure causes scarring in the front of the neck. Some of the scars heal well and merge with the neck 
wrinkles, but others may heal with hypertrophy. Naturally, patients want to avoid such visible scars $[10,14,17]$.

As a result, various surgical methods have been developed to minimize anterior neck scars or to allow scar formation in a location that can be easily covered. Several endoscopic approaches have been developed, including transaxillary and retro-auricular approaches. These surgical methods result in satisfactory cosmetic results and provide a wide surgical field of view with greater magnification [43]. However, the scars are often extensive and invasive, due to wide subcutaneous dissection of the chest and neck. Therefore, these scars do not correspond to those resulting from minimally invasive surgery, which has been discussed recently [19]. Thus, these endoscopic thyroidectomies are considered only as a "transition phase" between open surgery and truly non-invasive surgery.

Before performing transoral thyroid surgery, it is important to understand the anatomical safety zone from the mouth to the thyroid. Although transoral thyroidectomy using gas and a trocar has already been used in certain patients, mental nerve damage and $\mathrm{CO}_{2}$ gas-related complications (e.g., $\mathrm{CO}_{2}$ embolism) are still a concern [5,9,44].

Based on anatomical studies, we defined the range of the safety zone and applied it in transoral thyroidectomy [45]. The safety zone is trapezoidal in shape and located in the oral vestibule, so we made an inverted U-shaped incision on the vestibule. We then created an accessible passage using a retractor, which does not require the use of gas. This approach shows the feasibility of a gasless transoral approach, and allows access to the thyroid gland without any damage to the mental nerve and the facial nerve marginal branch. In addition, even large specimens can be removed intact without splitting or crushing through the incision site.

However, transoral thyroidectomy is not recommended for patients with tracheal invasion or anatomical defects, because this approach has only recently been developed and requires further refinement, and the above-mentioned study is just one of several trials. Nonetheless, it is anticipated that the transoral approach will eventually replace the transaxillary or bilateral axillo-breast approach, because it is less invasive and scar-free.

Gasless transoral thyroidectomy is characterized by three main features. First, it creates a safe zone for gasless oral thyroidectomy, which is precisely defined by anatomical landmarks and allows safe access to the thyroid gland without damaging the mental nerve or the mandibular marginal branch of facial nerve. Second, the working space is made by mechanical lifting without $\mathrm{CO}_{2}$ gas infusion, which not only provides a broader endoscopic view during surgery (without interference associated with smoke inhalation in gasless methods), but also avoids the complications associated with gas injection. The gasless method also allows operators to utilize instruments used in traditional thyroidectomy for flap incision or hemostasis. Third, a single large incision (without side-ports) provides a large working space and enables re- section of a large specimen intact without cutting or crushing. Further, four or five surgical devices (rather than three) can be used in a wide working space for retraction or manipulation. Therefore, this technique not only results in scarless outcomes, but also provides the surgeon with various surgical options for neck or chest disease.

\section{SURGICALTECHNIQUE (TRANSORALTHYROIDECTOMY)}

Following general anesthesia by nasal intubation, the lower lip is pulled with a retractor and a curved incision $4-5 \mathrm{~cm}$ in length is made in the vestibular mucosa. The safety zone is created via
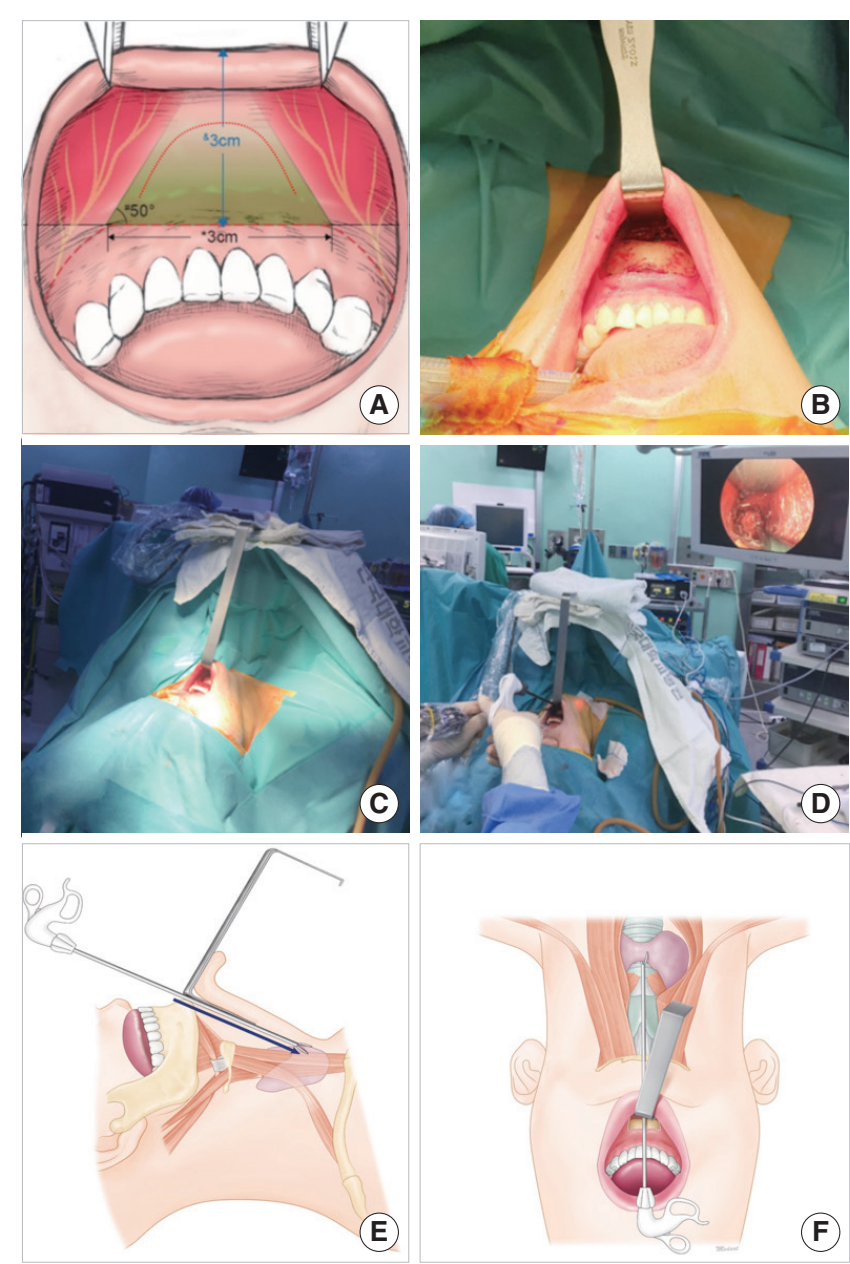

Fig. 4. Transoral thyroidectomy. (A) Safety zone and incision line (red dots). (B) The subplatysmal flap is retracted superiorly after creating a surgical path. (C) Operative view of transoral thyroidectomy. (D) Removal of the thyroid endoscopically. (E) Transoral approach for thyroid and perithyroid area. Anatomical view. Surgical approach to locate the thyroid gland. Elevation of a lower lip flap with a Sofield retractor. (F) Surgical view. Endoscopic dissector through the mucosal horizontal incision at the lower lip. 
a curved incision anteromedially at an angle of approximately $50^{\circ}$ to the horizontal plane of the lower lip between the canines. The curved incision, with its sides parallel to the lateral branch of the mental nerve, is made to expose the mandibular symphysis (Fig. 4).

An incision is made in the mucosal flap to expose the surface of the mentalis muscle. The mentalis muscle is then split near the ridge of the alveolar bone and a gradual incision is made. Using an electric scalpel, the surgeon separates the lower lip and jaw flaps from the surface of the mandible and retracts them to both sides. Lifting the vestibular flap with a retractor exposes the layer of the submental muscle and eventually reveals the suprahyoid muscle of the anterior neck. Space is subsequently generated under the subplatysmal layer along the mandible.

When the space is created under the subplatysmal layer of the anterior neck, the subplatysmal flap is lifted using a retractor and fixed above the patient's neck. Even without $\mathrm{CO}_{2}$ infusion, this anterior neck lift method efficiently creates a sufficient working space, resulting in a wide surgical field of view. An endoscope is inserted through the access for lighting and magnification. The strap muscles are split by cutting the midline and a fixed suture is made percutaneously to pull the strap muscles to both sides.

Following blunt dissection of the thyroid gland from the trachea, the thyroid isthmus is transected to facilitate the dissection of upper pole from the trachea with an endoscopic dissector and then ligated. Later, using a peanut dissector, the lateral part of the thyroid is dissected from the strap muscles. The middle thyroid vein is ligated as close to the thyroid as possible.

Anatomically, the recurrent laryngeal nerve (RLN) traverses downward as it enters the larynx parallel to the trachea of the tracheoesophageal groove. Therefore, the surgeon can easily identify the RLN by lifting the upper pole and the outer portion of
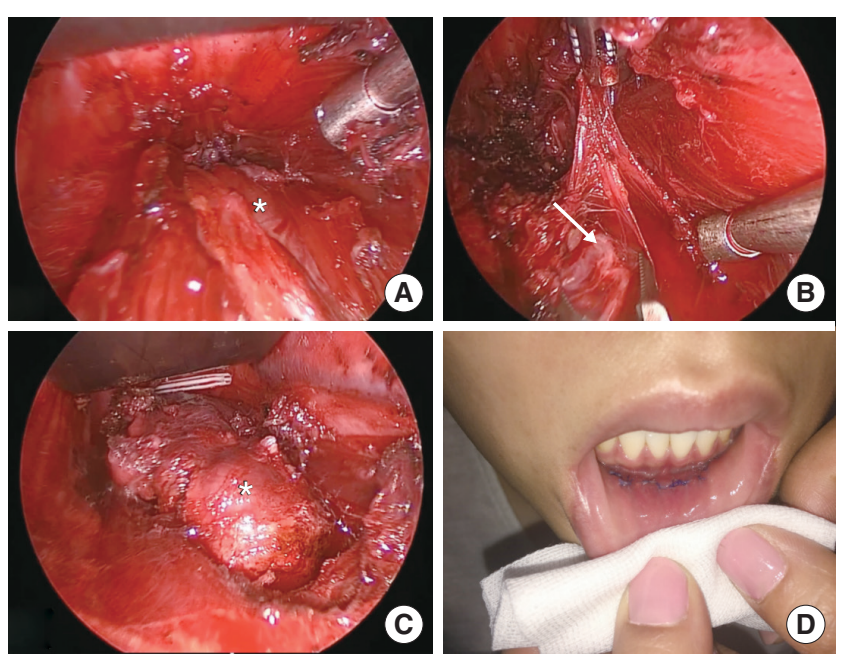

Fig. 5. Transoral thyroidectomy. (A) The subplatysmal flap is lifted to expose the strap muscle and thyroid (asterisk). (B) Dissection of the recurrent laryngeal nerve (white arrow). (C) Removal of the thyroid mass (asterisk). (D) One week after transoral thyroidectomy. the gland. After the RLN is identified and saved, the lower thyroid vessels are identified and dissected. Finally, the RLN is left in place and the thyroid gland is dissected (Fig. 5). Intact specimens can be removed through the incision site. The mentalis muscle is reattached with sutures to prevent jaw sagging. After thorough irrigation and hemostasis, the transoral surgical wound is closed using a 4-0 absorbent suture. A compression bandage around the chin is applied for 24 hours.

\section{DISCUSSION}

The surgical method described here is a cutting-edge technique designed to excise a midline neck mass via the oral cavity. Transoral treatment is associated with many benefits. First, the transoral approach does not result in scar formation. Postoperative cosmetic outcomes (including skin scars) are an important consideration in surgery of the head and neck area. The average age of patients with oral dermoid cysts is 20 to 30 years. The majority of patients who underwent thyroidectomy are women, approximately half of whom are young. Cosmetic concerns and demands are frequently expressed by young women and men. The major advantage of transoral surgery is an outstanding cosmetic outcome without scarring and the accompanying psychological satisfaction.

Second, the transoral approach reduces tissue damage and complications. Unlike the external approach, the transoral approach does not require skin incision, subcutaneous dissection, or mylohyoid muscle cutting. The transoral approach for dermoid cysts entails only incision on the frenulum and bilateral retraction of the GM, while an external approach causes damage to normal tissues (muscle, skin, and subcutaneous tissue), leaving a scar and resulting in additional problems from surgically affected normal tissues. Previous studies have reported satisfactory results after transoral TGDC resection in adults, as $97 \%$ of patients had no postoperative complications and achieved full preoperative function within a month. The transoral approach poses minimal damage to normal tissue and can efficiently and completely remove TGD [7,11-15,31,35,46]. The most anticipated complication during TGDC surgery is impaired breathing due to edema of the tongue. This surgical method covers the middle of the tongue and approaches the foreground, but does not actually damage the tongue muscles. In our experience, a swollen tongue was rare as the tissue was only detached and accessible. Moreover, except for the mucosal incision in the oral cavity, no other muscles were injured, and no postoperative complications involving either pronunciation or eating were detected because surgery was confined to the anatomical boundaries. Furthermore, the oral mucosa of the wound regenerates much faster than the other parts of the wound, so recovery is faster than that of a skin incision. Since the surgery involves areas close to the tongue, a few complications associated with pronunciation or swallowing may still occur post- 
operatively $[47,48]$. However, as mentioned earlier, this is not a problem because the surgical procedure does not actually damage the muscles of the tongue. In most cases, the surgical wound was clear after 3 months. Third, the transoral approach reduces the operation time $[47,49,50]$. Using an avascular space created via bilateral retraction of the GMs results in minimal bleeding and reduces the number of surgical steps, thereby decreasing the overall time required.

However, transoral surgery also has its limitations. The main issue with transoral surgery is wound contamination [49,51-54]. Transcervical surgery is considered a "clean" operation, obviating the need for antibiotics. Nonetheless, transoral thyroid surgery is used for type II (clean-contaminated) wounds, in which the surgical field and incision area are clean, but the lower vestibule is contaminated. For this reason, antibiotics and an oral gargle are prescribed after surgery. Follow-up monitoring for 12 months postoperatively showed no additional complications.

\section{CONCLUSION}

This review presents endoscopically-assisted scar-free excision of head and neck midline masses. Excision of transoral midline neck masses is a highly recommended alternative surgical option for procedures involving the head and neck, as well as the chest, and is expected to eventually replace conventional skin incisions in the future.

\section{CONFLICT OF INTEREST}

Seung Hoon Woo is an associate editor of the journal but was not involved in the peer reviewer selection, evaluation, or decision process of this article. No other potential conflicts of interest relevant to this article were reported.

\section{ACKNOWLEDGMENTS}

This research was supported by the research fund of Dankook University in 2020.

\section{ORCID}

Hyoyeon Kim https://orcid.org/0000-0002-4653-0387

Seung Hoon Woo https://orcid.org/0000-0001-7560-1140

\section{AUTHOR CONTRIBUTIONS}

Conceptualization: SHW. Data curation: SHW. Formal analysis:
SHW. Funding acquisition: SHW. Methodology: SHW. Project administration: SHW. Visualization: HK. Writing-original draft: HK.Writing-review \& editing: HK.

\section{REFERENCES}

1. Park JO. Facelift approach for resecting benign upper neck masses. World J Surg. 2017 Jun;41(6):1488-93.

2. Rumsey N, Clarke A, White P. Exploring the psychosocial concerns of outpatients with disfiguring conditions. J Wound Care. 2003 Jul; 12(7):247-52.

3. Gagner M, Inabnet WB 3rd. Endoscopic thyroidectomy for solitary thyroid nodules. Thyroid. 2001 Feb;11(2):161-3.

4. Lee HS, Lee D, Koo YC, Shin HA, Koh YW, Choi EC. Endoscopic resection of upper neck masses via retroauricular approach is feasible with excellent cosmetic outcomes. J Oral Maxillofac Surg. 2013 Mar; 71(3):520-7.

5. Kim JP, Lee DK, Moon JH, Park JJ, Woo SH.Transoral dermoid cyst excision: a multicenter prospective observational study. Otolaryngol Head Neck Surg. 2018 Dec;159(6):981-6.

6. Kim JP, Park JJ, Jeon SY,Ahn SK, Hur DG, Kim DW, et al. Endoscopeassisted intraoral resection of external dermoid cyst. Head Neck. 2012 Jun;34(6):907-10.

7. Kim JP, Park JJ, Lee EJ,Woo SH. Intraoral removal of a thyroglossal duct cyst using a frenotomy incision. Thyroid. 2011 Dec;21(12): 1381-4.

8. Kim JP, Park JJ, Park HW,Woo SH. Endoscopy-assisted resection of a submandibular gland mass via a thyroidectomy incision. Ear Nose Throat J. 2015 Sep;94(9):E30-3.

9. Kim JP, Park JJ, Woo SH. No-scar transoral thyroglossal duct cyst excision in children. Thyroid. 2018 Jun;28(6):755-61.

10. Woo SH. Endoscopic-assisted total thyroidectomy via lateral keloid scar incision. Clin Exp Otorhinolaryngol. 2014 Dec;7(4):338-41.

11. Woo SH. Endoscope-assisted transoral thyroidectomy using a frenotomy incision. J Laparoendosc Adv Surg Tech A. 2014 May;24(5): 345-9.

12. Woo SH. Endoscope-assisted transoral accessory parotid mass excision. Head Neck. 2016 Jan;38(1):E7-12.

13. Woo SH, Jeong HS, Kim JP, Park JJ, Baek CH. Endoscope-assisted intraoral removal of ectopic thyroid tissue using a frenotomy incision. Thyroid. 2013 May;23(5):605-8.

14. Woo SH, Jeong HS, Kim JP, Park JJ, Baek CH. Endoscope-assisted frenotomy approach to median upper neck masses: clinical outcomes and safety (from a phase II clinical trial). Head Neck. 2014 Jul;36(7): 985-91.

15. Woo SH, Kim JP, Baek CH. Endoscope-assisted extracapsular dissection of benign parotid tumors using hairline incision. Head Neck. 2016 Mar;38(3):375-9.

16. Clark MP, Qayed ES, Kooby DA, Maithel SK, Willingham FF. Natural orifice translumenal endoscopic surgery in humans: a review. Minim Invasive Surg. 2012;2012:189296.

17. Anuwong A. Transoral endoscopic thyroidectomy vestibular approach: a series of the first 60 human cases. World J Surg. 2016 Mar;40(3): 491-7.

18. Anuwong A, Ketwong K, Jitpratoom P, Sasanakietkul T, Duh QY. Safety and outcomes of the transoral endoscopic thyroidectomy vestibular approach. JAMA Surg. 2018 Jan;153(1):21-7.

19. Kim HY, Chai YJ, Dionigi G, Anuwong A, Richmon JD. Transoral robotic thyroidectomy: lessons learned from an initial consecutive series of 24 patients. Surg Endosc. 2018 Feb;32(2):688-94.

20. Turetschek K, Hospodka H, Steiner E. Case report: epidermoid cyst 
of the floor of the mouth: diagnostic imaging by sonography, computed tomography and magnetic resonance imaging. Br J Radiol. 1995 Feb;68(806):205-7.

21. Zachariades N, Skoura-Kafoussia C. A life-threatening epidermoid cyst of the floor of the mouth: report of a case. J Oral Maxillofac Surg. 1990 Apr;48(4):400-3.

22. Calderon S, Kaplan I. Concomitant sublingual and submental epidermoid cysts: a case report. J Oral Maxillofac Surg. 1993 Jul;51(7): 790-2.

23. Longo F, Maremonti P, Mangone GM, De Maria G, Califano L. Midline (dermoid) cysts of the floor of the mouth: report of 16 cases and review of surgical techniques. Plast Reconstr Surg. 2003 Nov;112(6): 1560-5.

24. AriyoshiY, Shimahara M. Magnetic resonance imaging of a submental dermoid cyst: report of a case. J Oral Maxillofac Surg. 2003 Apr; 61(4):507-10.

25. Bodner L, Woldenberg Y, Sion-Vardy N. Dermoid cyst of the maxilla. Int J Oral Maxillofac Surg. 2005 Jun;34(4):453-5.

26. Woo SH, Park JJ, Kwon M, Kim JP. "Hidden scar" submandibular gland excision using an endoscope-assisted hairline approach. Oral Oncol. 2017 Feb;65:83-8.

27. Kim HS, Chung SM, Pae SY, Park HS. Endoscope assisted submandibular sialadenectomy: the face-lift approach. Eur Arch Otorhinolaryngol. 2011 Apr;268(4):619-22.

28. Akao I, Nobukiyo S, Kobayashi T, Kikuchi H, Koizuka I. A case of large dermoid cyst in the floor of the mouth. Auris Nasus Larynx. 2003 Feb;30 Suppl:S137-9.

29. Leveque H, Saraceno CA, Tang CK, Blanchard CL. Dermoid cysts of the floor of the mouth and lateral neck. Laryngoscope. 1979 Feb; 89(2 Pt 1):296-305.

30. Radkowski D, Arnold J, Healy GB, McGill T, Treves ST, Paltiel H, et al. Thyroglossal duct remnants: preoperative evaluation and management. Arch Otolaryngol Head Neck Surg. 1991 Dec;117(12):1378-81.

31. Allard RH. The thyroglossal cyst. Head Neck Surg. 1982 Nov-Dec; 5(2):134-46.

32. Sammarco GJ, Mc Kenna J. Thyroglossal duct cysts in the elderly. Geriatrics. 1970 Aug;25(8):98-101.

33. Hussain K, Henney S, Tzifa K. A ten-year experience of thyroglossal duct cyst surgery in children. Eur Arch Otorhinolaryngol. 2013 Nov; 270(11):2959-61.

34. Marianowski R, Ait Amer JL, Morisseau-Durand MP, Manach Y, Rassi S. Risk factors for thyroglossal duct remnants after Sistrunk procedure in a pediatric population. Int J Pediatr Otorhinolaryngol. 2003 Jan;67(1):19-23.

35. Woo SH, Park JJ, Hong JC, Wang SG, Park GC, Eun YG, et al. Endoscope-assisted transoral removal of a thyroglossal duct cyst using a frenotomy incision: a prospective clinical trial. Laryngoscope. 2015 Dec;125(12):2730-5

36. Lin ST,Tseng FY, Hsu CJ,YehTH, Chen YS. Thyroglossal duct cyst: a comparison between children and adults. Am J Otolaryngol. 2008
Mar-Apr;29(2):83-7.

37. Maddalozzo J, Venkatesan TK, Gupta P. Complications associated with the Sistrunk procedure. Laryngoscope. 2001 Jan;111(1):119-23.

38. Mondin V, Ferlito A, Muzzi E, Silver CE, Fagan JJ, Devaney KO, et al. Thyroglossal duct cyst: personal experience and literature review. Auris Nasus Larynx. 2008 Mar;35(1):11-25.

39. Perkins JA, Inglis AF, Sie KC, Manning SC. Recurrent thyroglossal duct cysts: a 23-year experience and a new method for management. Ann Otol Rhinol Laryngol. 2006 Nov;115(11):850-6.

40. Shah R, Gow K, Sobol SE. Outcome of thyroglossal duct cyst excision is independent of presenting age or symptomatology. Int J Pediatr Otorhinolaryngol. 2007 Nov;71(11):1731-5.

41. Brousseau VJ, Solares CA, Xu M, Krakovitz P, Koltai PJ.Thyroglossal duct cysts: presentation and management in children versus adults. Int J Pediatr Otorhinolaryngol. 2003 Dec;67(12):1285-90.

42. Lee JS, Kim JP, Ryu JS, Woo SH. Effect of wound massage on neck discomfort and voice changes after thyroidectomy. Surgery. 2018 Nov;164(5):965-71.

43. Huscher CS, Chiodini S, Napolitano C, Recher A. Endoscopic right thyroid lobectomy. Surg Endosc. 1997 Aug;11(8):877.

44. Henry JF, Sebag F. Lateral endoscopic approach for thyroid and parathyroid surgery. Ann Chir. 2006 Jan;131(1):51-6.

45. Yang HM, Shin KJ, Min J, Woo SH. Anatomical study of gasless transoral thyroidectomy and clinical application. Surg Endosc. 2020 Aug; 34(8):3414-23.

46. Woo SH. Endoscope-assisted intraoral removal of the thyroid isthmus mass using a frenotomy incision. J Laparoendosc Adv Surg Tech A. 2013 Sep;23(9):787-90.

47. Tae K. Complications of transoral thyroidectomy: overview and update. Clin Exp Otorhinolaryngol. 2021 May;14(2):169-78.

48. Hong YT, Woo SH. Robotic modified radical neck dissection through the bilateral axillary breast approach. Clin Exp Otorhinolaryngol. 2021 Feb;14(1):13-4.

49. Kim SI, Min HK, Kang DW, Choi SY, Kang HJ, Lee YC, et al. Modified transoral endoscopic thyroidectomy technique using trapdoor suspension sutures. Clin Exp Otorhinolaryngol. 2021 Mar 30 [Epub]. https://doi.org/10.21053/ceo.2021.00101.

50. Tae K. Transoral thyroidectomy: is it a real game changer? Clin Exp Otorhinolaryngol. 2020 May;13(2):93-4.

51. Tae K, Ji YB, Song CM, Ryu J. Robotic and endoscopic thyroid surgery: evolution and advances. Clin Exp Otorhinolaryngol. 2019 Feb;12(1):1-11.

52. Padalhin AR. Lasers and robots: recent developments in transoral laser and transoral robotic surgery. Med Lasers. 2020 Dec;9(2): 103-9.

53. Lee SJ, Chung PS, Chung SY,Woo SH. Transoral laser excision of a pyriform sinus cyst. Med Lasers. 2019 Dec;8(2):84-6.

54. Hong JC, Lee KD. Transoral laser surgery for supraglottic carcinoma. Med Lasers. 2013 Jun;2(1):1-7. 